\title{
MULTI-SCALE MODELLING OF THE CIRCE-HERO FACILITY
}

\author{
K. Zwijsen*, D. Martelli, P.A. Breijder*, N. Forgione ${ }^{\circ}$ and F. Roelofs* \\ * NRG, Westerduinweg 3, Petten, Netherlands \\ ${ }^{\circ}$ University of Pisa, Department of Civil and Industrial Engineering, Pisa, Italy
}

\begin{abstract}
This work describes the activities performed at the University of Pisa (UniPi) and at the Nuclear Research and Consultancy Group (NRG) concerning the application of different in-house developed coupling methodologies for thermal-hydraulic analysis of innovative nuclear reactor.

The application of a tool for System Thermal-Hydraulic (STH) and Computational Fluid Dynamics (CFD) coupled calculations aims at exploiting the advantages from both the codes to perform thermal-hydraulic analysis of complex systems restricting a higher-degree of detail in a smaller part of the domain. Indeed, STH codes are commonly used for thermal-hydraulic analysis of entire complex nuclear systems, though these codes become generally inadequate to investigate phenomena with relevant 3D characteristics, such as mixing and thermal stratification in large pool systems. On the other hand, the exclusive use of CFD codes to simulate large systems is still too demanding in term of computational efforts. In such frame, the coupling between two or more scales represent a promising compromise, especially for those applications in which the small-scale phenomena take place in a limited part of the domain. Two different models of the CIRCE facility are created. At NRG, the CFD code ANSYS CFX is coupled with the STH code SPECTRA, while at UniPi, ANSYS Fluent is used for the CFD calculations and a modified version of RELAP5 is adopted for the STH calculations. Modelling and coupling strategies for both models are discussed in the present paper. Furthermore, simulation results of both models are here discussed, both for steady-state cases representing experiments at full power, as well as Protected Loss Of Heat sink and Loss Of Flow (PLOH + LOF) accident scenarios. Special attention is paid to pool phenomena such as the $3 \mathrm{D}$ characteristic of the heavy-liquid metal (Lead-Bismuth Eutectic, LBE) fluid flow, the thermal stratification and the temperature evolution during the postulated transients.
\end{abstract}

\section{INTRODUCTION}

In order to enhance the safety standards and culture of Liquid Metal Fast Reactors (LMFR), it's important to provide the system designers with accurate information and data. Because of a general lack of experimental data relating to accident scenarios, such as loss of flow (pump breaking down) or loss of heat sink (heat exchanger malfunction), the use of numerical simulations (e.g. thermal-hydraulics analysis) remains a valid support in predicting coolant flow and thermal behaviour in such scenarios.

Historically, the primary computational tool to study the reactor's behaviour are System Thermal-Hydraulic (STH) codes. These were initially designed and validated to be used for Light Water Reactors (LWRs) but have recently been adopted for application of liquid metals as coolant in LMFRs. The advantage of using STH codes is that they require relatively low computational efforts as they are often 1D and/or use a relatively coarse nodalization in 3D. The drawback though is that no details of the flow and temperature fields are resolved.

With the increase in computer power and capacity, and the advancements being made in numerical modelling, nowadays it is possible to resolve the full flow and thermal fields of the reactor on a, relatively, fine and detailed scale using Computational Fluid Dynamics (CFD). This has as clear advantage that the flow and thermal fields can be studied in detail. However, to simulate accident scenario's occurring in a nuclear reactor, long transients have to be simulated, which costs a lot of computational power and time if a CFD code is used.

Multi-scale modelling combines the best of both worlds; it uses CFD where detailed solutions are desired and STH codes where 1D solutions give accurate enough solutions, allowing the simulation time to remain manageable. The focus of this paper is on multi-scale modelling of the Italian CIRColazione Eutettico (CIRCE) heavy liquid-metal pool-type facility built at ENEA Brasimone. Within the European Horizon 2020 projects called SESAME (thermal hydraulics Simulations and Experiments for the Safety Assessment of MEtal cooled reactors) and MYRTE (MYRRHA Research and Transmutation Endeavour), several experiments are designed in the CIRCE facility to mimic hypothetical accident scenarios occurring inside a liquid metal cooled reactor. Results coming from the foreseen experimental campaigns are, where possible, used to assess and improve the developed models.

Two different models of the CIRCE facility are created. At NRG, the CFD code CFX is coupled with the STH code SPECTRA, while at UniPi, Fluent is used for the CFD calculations and a modified version of RELAP5 (RELAP5/Mod3.3) is adopted for the STH calculations. Modelling and coupling strategies for both models are discussed in the present paper. Furthermore, simulation results of both models are compared with each other, both for steady-state cases representing experiments at full power, as well as Protected Loss Of Heat sink and Loss Of Flow (PLOH + LOF) accident scenarios. Special attention is paid to pool phenomena such 
as the 3D characteristic of the heavy-liquid metal (Lead-Bismuth Eutectic, LBE) fluid flow, the thermal stratification and the temperature evolution during the postulated transients.

\section{CIRCE-HERO EXPERIMENTAL FACILITY}

CIRCE (CIRcolazione Eutettico) (Bandini et al., 2001, Tarantino et al., 2011, Tarantino et al., 2015) is an integral effect pool type facility designed and realized at the ENEA Brasimone Research Centre consisting of a cylindrical vessel (Main Vessel S100) filled with about 70 tons of molten Lead-Bismuth Eutectic (LBE) with argon cover gas and recirculation system, LBE heating and cooling systems. In the frame of the SESAME Project the facility was refurbished with the Heavy liquid mEtal - pRessurized water cOoled tube (HERO, Rozzia et al., 2017) test section for characterizing a new steam generator concept foreseen for the Advanced Lead Fast Reactor European Demonstrator (ALFRED) reactor (Frignani et al. 2017). The HERO steam generator bayonet tube is a 1:1 mock-up representative of the ALFRED steam generator, it consists of seven double-walls bayonet tubes arranged in a hexagonal shroud (the bayonet tube dimensions are summarized in Table 1) with stainless steel powder filling the gap and with intermediate leakage monitoring. The secondary circuit of the HERO heat exchanger is fed by pressurized water (180 bar) and it has a thermal duty of about $500 \mathrm{~kW}$.

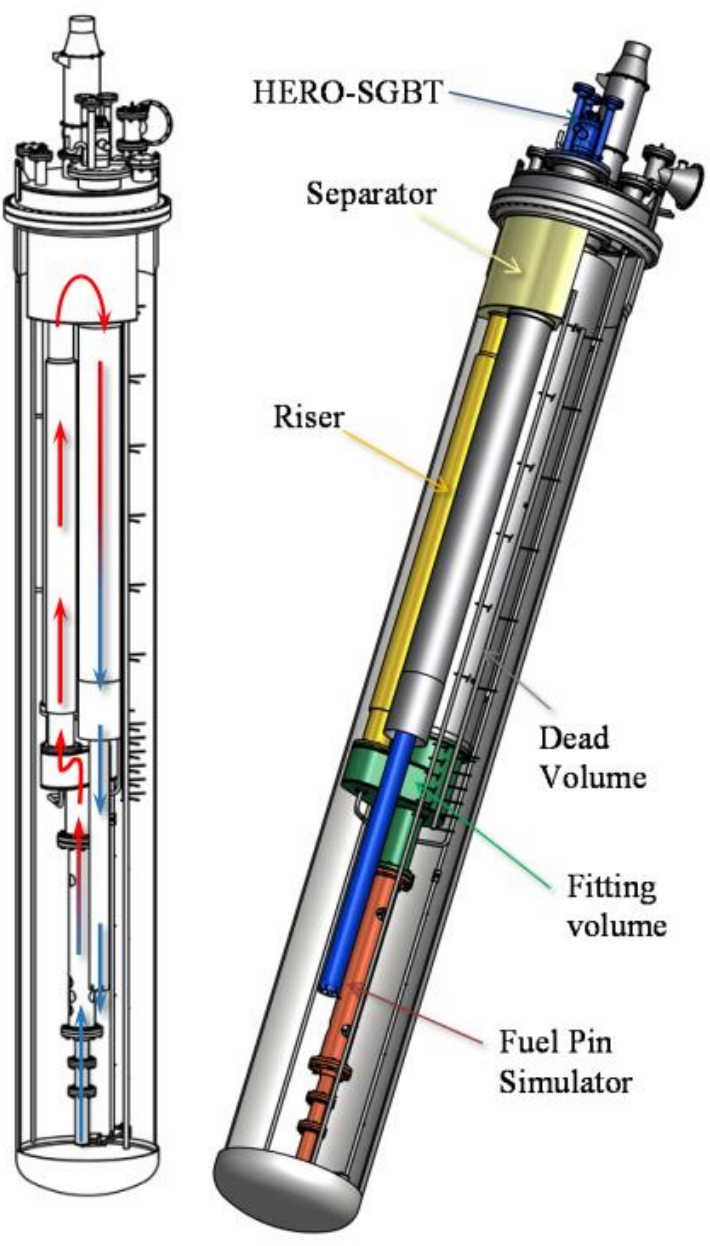

(a)

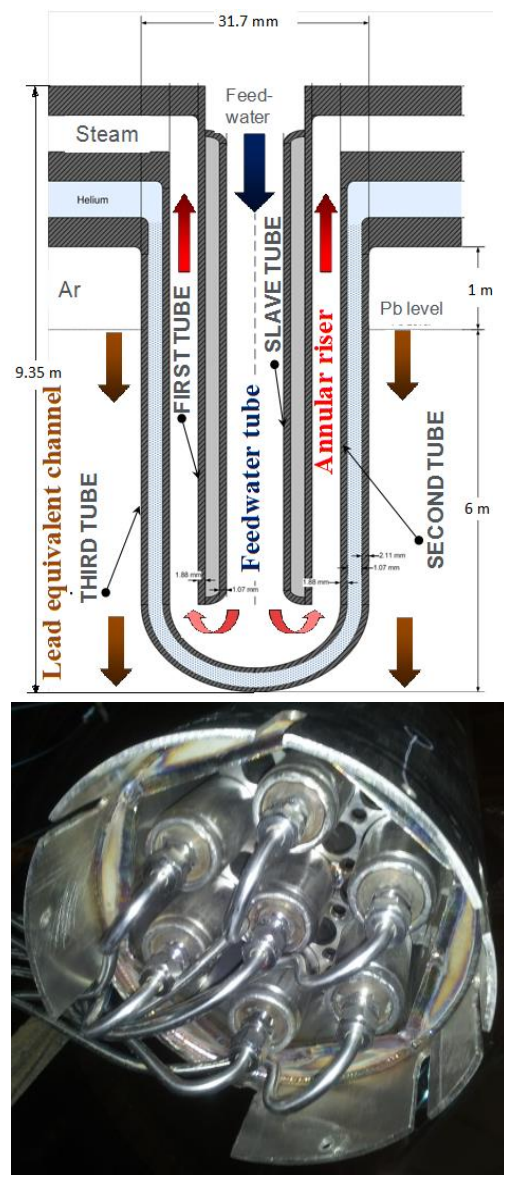

(b)

Figure 1: CIRCE pool(a) and HERO SGBT (b)

The feed-water enters the unit at the top edge of the slave tube, it flows downward and it is collected into the lower plenum. Then water flows upward through the annular riser between the first and second tube and the superheated steam is collected into the steam chamber. The gap between slave and first tube is filled with air (slight vacuum) as insulator to avoid steam condensation. The gap between second and third tube is filled with AISI316L powder and slightly pressurized helium (10 bar) to detect any leakages, monitoring helium pressure, and while maintaining excellent heat exchange capability, thanks to the metallic powder. The ends of the bayonet tubes are closed with a welded steel cap. The LBE mass flow rate in the facility under forced circulation conditions is obtained by setting a proper argon mass flow rate in the riser tube (see Figure 1) simulating the driving force of a pumping system (gas enhanced circulation). In the separator the argon gas is then separated from the LBE and recirculated from the cover gas outside the main vessel in the argon loop to maintain the pressure in the cover gas almost constant.

Table 1: HERO SGBT: tube design

\begin{tabular}{|c|l|l|c|}
\hline Label & Outer Diameter [mm] & Thickness [mm] & Material \\
\hline Slave Tube & 9.53 & 1.22 & AISI 304 \\
\hline First Tube & 19.05 & 1.65 & AISI 304 \\
\hline Second Tube & 25.40 & 2.11 & AISI 304 \\
\hline
\end{tabular}




\begin{tabular}{|l|l|l|l|}
\hline Third Tube & 33.40 & 3.38 & AISI 304 \\
\hline
\end{tabular}

\section{SIMULATION TEST MATRIX}

The performed simulations regard pre- and post-tests analyses of the CIRCE-HERO experimental campaign developed in the frame of the SESAME Project. In particular, the activities carried out at the University of Pisa deals with the pre-test simulations of two cases representative of a Protected Loss Of Flow Accident (PLOFA, namely Test 1 and Test 3). The nominal initial conditions for both the tests are summarized in Table 2.

Table 2: Nominal initial conditions (Test 1 and 3)

\begin{tabular}{|l|c|}
\hline \multicolumn{2}{|c|}{ Initial nominal conditions (Test 1, 3) } \\
\hline FPS Power $[\mathrm{kW}]$ & 450 \\
\hline Pool initial T $\left[{ }^{\circ} \mathrm{C}\right]$ & 400 \\
\hline$\Delta \mathrm{T}$ across the FPS $\left[{ }^{\circ} \mathrm{C}\right]$ & 80 \\
\hline Feed-water pressure $[\mathrm{bar}]$ & 172 \\
\hline Feed-water inlet $\mathrm{T}\left[{ }^{\circ} \mathrm{C}\right]$ & 355 \\
\hline Feed-water mass flow $[\mathrm{kg} / \mathrm{s}]$ & 0.33 \\
\hline Heat losses $[\mathrm{kW}]$ & 15 \\
\hline
\end{tabular}

For the considered tests, the electrical power supplied to the Fuel Pin Simulator (FPS) from the full power condition (450 kW corresponding to $100 \%$ ) is decreased down to $22.5 \mathrm{~kW}$ to simulate the decay heat (5\% of the nominal power) according to Table 3 .

\section{Table 3: FPS Nominal time trend (Test 1 and 3)}

\begin{tabular}{|c|c|}
\hline \multicolumn{2}{|c|}{ FPS Power time } \\
\hline Time [s] & FPS Power [\%] \\
\hline 0 & $100 \%$ \\
\hline 1 & $90 \%$ \\
\hline 2 & $83 \%$ \\
\hline 2 & $77 \%$ \\
\hline 4 & $71 \%$ \\
\hline 5 & $67 \%$ \\
\hline 10 & $50 \%$ \\
\hline 20 & $33 \%$ \\
\hline 30 & $25 \%$ \\
\hline 50 & $17 \%$ \\
\hline 100 & $9 \%$ \\
\hline 150 & $5 \%$ \\
\hline 200 & $2 \%$ \\
\hline $300-1000$ & $0 \%$ \\
\hline
\end{tabular}

As the gas flow rate is concerned, its value is decreased to 0 in $10 \mathrm{~s}$ for Test $1 \mathrm{NC}$ to simulate the pump trip, while for Test $3 \mathrm{NC}$ the gas flow rate is reduced according to Table 4 to simulate the slow deceleration after the pump trip (because of the flywheel inertia).

Table 4: Gas injection nominal time trend
\begin{tabular}{|c|c|}
\hline Gas Injection time trend \\
\hline Time $[\mathrm{s}]$ & Gas mfr [\%] \\
\hline 0 & $100 \%$ \\
\hline 1 & $25 \%$ \\
\hline 2 & $22 \%$ \\
\hline 3.5 & $19 \%$ \\
\hline 5 & $17 \%$ \\
\hline 7.5 & $15 \%$ \\
\hline 10 & $14 \%$ \\
\hline 15 & $12 \%$ \\
\hline 22.5 & $10 \%$ \\
\hline 30 & $9 \%$ \\
\hline $40-50$ & $8 \%$ \\
\hline 60 & $7 \%$ \\
\hline $90-180$ & $6 \%$ \\
\hline $240-1000$ & $5 \%$ \\
\hline
\end{tabular}

Finally, the HERO feedwater mass flow rate is decreased to $0.033 \mathrm{~kg} / \mathrm{s}(10 \%$ of the nominal value) to simulate the activation of the Decay Heat Removal system (DHR).

Concerning the activities performed at NRG, attention is focused on the post-test simulation of Test 3 . It must be underlined that there are differences between the initial conditions of the experiments (as performed) and the nominal initial conditions (as designed) 
reported in Table 3. The actual initial conditions of Test 3 are reported in Table 5 . The heat losses from the facility to the environment are evaluated according to the experimental test reported in A. Pesetti, 2018.

Table 5: Experimental initial conditions (Test 3)
\begin{tabular}{|l|c|}
\hline \multicolumn{2}{|c|}{ Initial experimental conditions (Test 3) } \\
\hline FPS Power $[\mathrm{kW}]$ & 356 \\
\hline Pool initial T $\left[{ }^{\circ} \mathrm{C}\right]$ & $\sim 419.5$ \\
\hline$\Delta$ T across the FPS $\left[{ }^{\circ} \mathrm{C}\right]$ & $\sim 75$ \\
\hline Feed-water pressure $[\mathrm{bar}]$ & 171 \\
\hline Feed-water inlet T $\left[{ }^{\circ} \mathrm{C}\right]$ & $\sim 336.7$ \\
\hline Feed-water mass flow $[\mathrm{kg} / \mathrm{s}]$ & 0.294 \\
\hline Heat losses $[\mathrm{kW}]$ & $\begin{array}{c}\text { Experimentally } \\
\text { evaluated }\end{array}$ \\
\hline
\end{tabular}

\section{PRE-TEST SIMULATIONS AT UNIPI}

\subsection{RELAP5 stand-alone geometrical model}

The complete CIRCE-HERO RELAP5/Mod3.3 computational domain is reported in Figure 2. The model is composed of three main zones: the pool, the test section and the HERO SG secondary water side. The pool is mainly composed of parallel pipes (in light blue) connected at the beginning and at the end by means of branches (in dark blue). Cross-junctions are also used to connect the nodes composing each pipe. The test section (upward and downward tubes guiding the LBE through the FPS and the HERO DWBT-SG) is schematized as a succession of pipes (light red) and branches (dark red).

The argon injection system is simulated with a time-dependent volume ("TDPV 3" in Figure 2) and with a junction having imposed argon flow rate $\left([\mathrm{Nl} / \mathrm{s}]\right.$, normal condition considered $@ \mathrm{~T}=0^{\circ} \mathrm{C}$ and $\left.\mathrm{P}=1 \mathrm{~atm}\right)$. The gas mass flow rate then generate an averaged reduced density in the riser driving upward the LBE and hence promoting forced circulation conditions. The value of the LBE mass flow rate is therefore an output of the simulation. The last part of the model is the secondary side of HERO SG. The feedwater properties $\left(\sim 17.2 \mathrm{MPa}\right.$ and $\left.335^{\circ} \mathrm{C}\right)$ and mass flow rate are imposed with a time-dependent volume (no. 410$)$. The feedwater then splits into two streams: the first crosses the volumes simulating the central bundle tube (volumes no. $4^{* *}$ ), and the second crosses the volumes simulating the remaining six lateral bundle tubes lumped together (volumes no. $5^{* *}$ ). Except for branches no. 418, 435, and 460 (in dark green), all the other volumes are pipes (light green). Two structures (in yellow) reproduce the heat transfer regions of the HERO SG. These two structures are composed of (from the inside to the outside) $2.11 \mathrm{~mm}$ of stainless steel (AISI 304), $0.62 \mathrm{~mm}$ of a mixture of stainless-steel powder (AISI 316) and helium gas, and $3.38 \mathrm{~mm}$ of stainless steel (AISI 304) (Table 2). This computational model was adopted for STH stand-alone calculation.

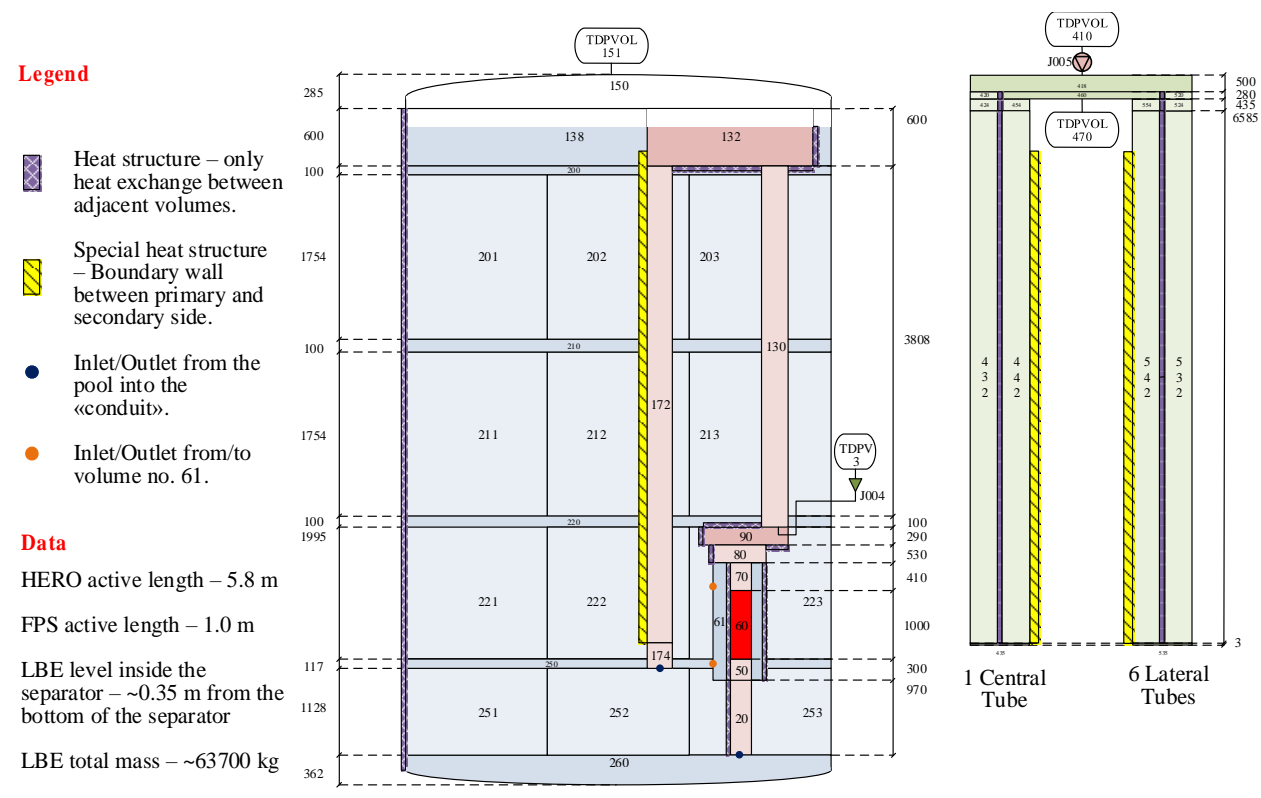

Figure 2: CIRCE-HERO RELAP5/Mod3.3 nodalization

\subsection{CFD geometrical model}

The CFD code ANSYS Fluent was employed to model the main vessel of CIRCE-HERO facility. A 3D geometrical domain (see Figure 2) was developed to reproduce the LBE domain of the pool and the complementary space occupied by the HERO test section (non-calculation domain in the CFD model). The discretization of the geometrical model is composed of $1.83 \cdot 10^{6}$ cells (mainly structured elements, except for the rounded bottom region). The thickness of the first cell close to the wall is such that the "standard wall function" was used for the wall treatment and the $R N G k-\varepsilon$ model was chosen to consider the effect of the turbulent flow. 

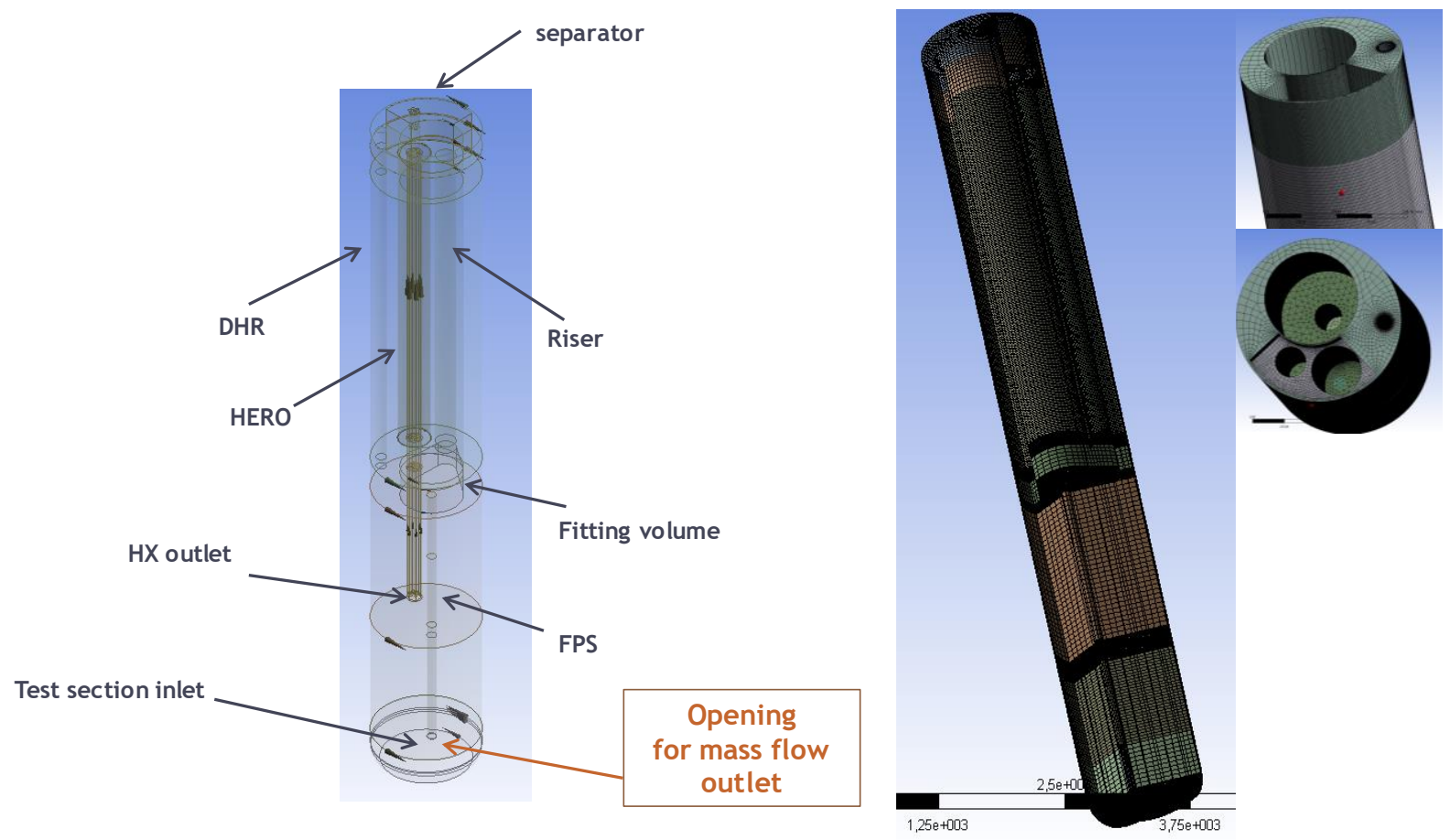

Figure 3:HERO CFD computational model

\subsection{RELAP5/Fluent coupling procedure}

The coupling approach between the RELAP5/Mod 3.3 and Ansys Fluent developed at the UniPi (Angelucci M. et al., 2017, Martelli et al., 2017) uses a "non-overlapping", "two-way" coupling scheme. The overall domain is divided into regions modelled using the CFD approach (generally regions where effects of turbulence and 3D phenomena are relevant,) and other regions modelled using a system code (generally regions where two-phase flow occurs). This strategy allows the use of the most appropriate code where necessary, in the current application the pool is simulated by the CFD code while the test section including the secondary HERO water side is simulated by the STH code.

Starting from the RELA5 stand-alone computational domain shown in Figure 2 the nodalization of the HERO test section (including the HERO secondary water side) is extracted and two time dependent volume (TDV) are introduced (TDV-10 and TDV-180 see Figure 4 (a)) and used as boundary interfaces between the two codes in the coupled simulation. Indeed, different regions are connected by one or more "coupling" interfaces where the thermo-fluid-dynamics data are transferred from the CFD-code to the STH-code-region and vice versa ("two-way coupling"). Each code solves independently its own set of balance equations ("partitioned solution method") while an appropriate MATLAB script handles the codes synchronization, drives the execution of both the solvers, enables the exchange and processes the data when required (see the flow diagram reported in Figure 4 (b)). Several and different physical parameters (e.g. mass flow, velocity, pressure, temperature, etc.) can be passed at each interface. For the current application, the CFD code transfers to RELAP5 the pressures at both inlet and outlet section of HERO test section, whereas the RELAP5 code transfers the mass flow rate at the inlet and outlet of the pool (CFD domain). The temperature at the exit of the HX is passed to the Fluent pool inlet by RELAP5 and vice versa, Fluent gives the temperature at the inlet of HERO test section to the RELAP5 domain (through time-dependent volume 10). Moreover, atmospheric pressure at the cover gas was set as boundary condition to both the domains: at the top of the pool, in the Volume Of Fluid (VOF) region of the Fluent domain, and at the top of the separator of the test section in the RELAP5 domain (through time-dependent volume 151). In order to account heat transfer phenomena between the test section and the pool a thermal coupling between part of the RELAP5 and CFD domains is considered. In these preliminary calculations the heat transfer between the fitting volume, the separator (simulated in the RELAP5 domain) and the LBE pool (simulated in the CFD domain) is considered. To this end, the LBE temperatures adjacent to the fitting volume and to the separator are evaluated by the Fluent CFD code and passed as variables to RELAP5 (imposed as general table card for temperature boundary conditions). RELAP5 in turn passes to Fluent the heat transfer coefficient (HTC) and the temperature inside the considered volumes (separator and fitting volume) used as bulk temperature in the CFD boundary condition.

In a generic coupling iteration, the CFD simulation is launched first (master code), with mass flow rates m (exiting from the pool), $\dot{\mathrm{m}}$ (entering in the pool) and temperature $\mathrm{T}_{2}$ at the pool inlet as boundary conditions, using the data obtained from the previous RELAP5 simulation. For the first coupling iteration, results from a RELAP5 standalone simulation are used as BC for the first Fluent simulation. From the CFD results, pressure data $\mathrm{p}_{1}$ and $\mathrm{p}_{2}$ and the temperature $\mathrm{T}_{1}$ at the test section inlet (pool outlet) are given to RELAP5 as boundary conditions in TDV-10 and TDV-180. 


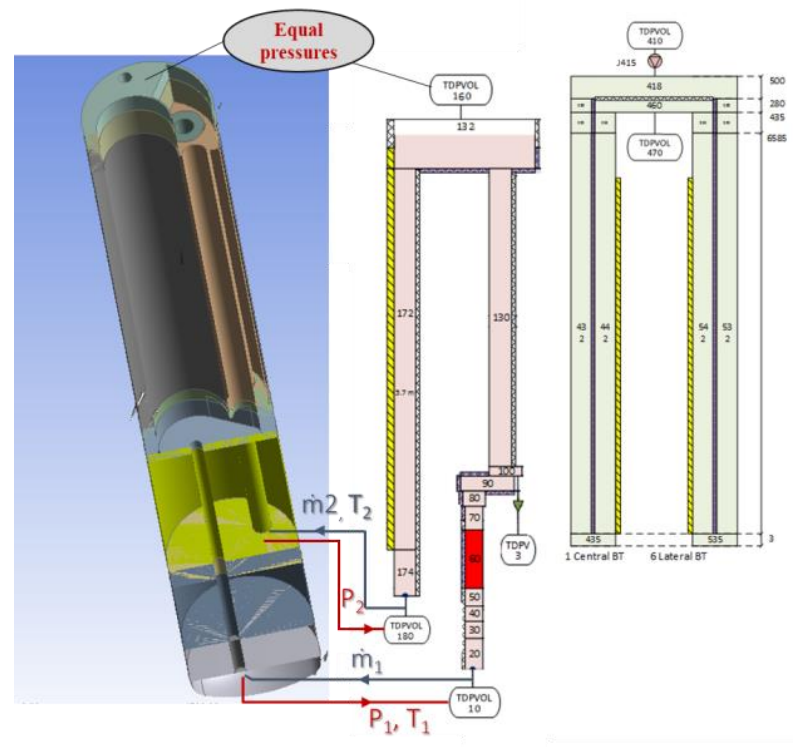

(a)

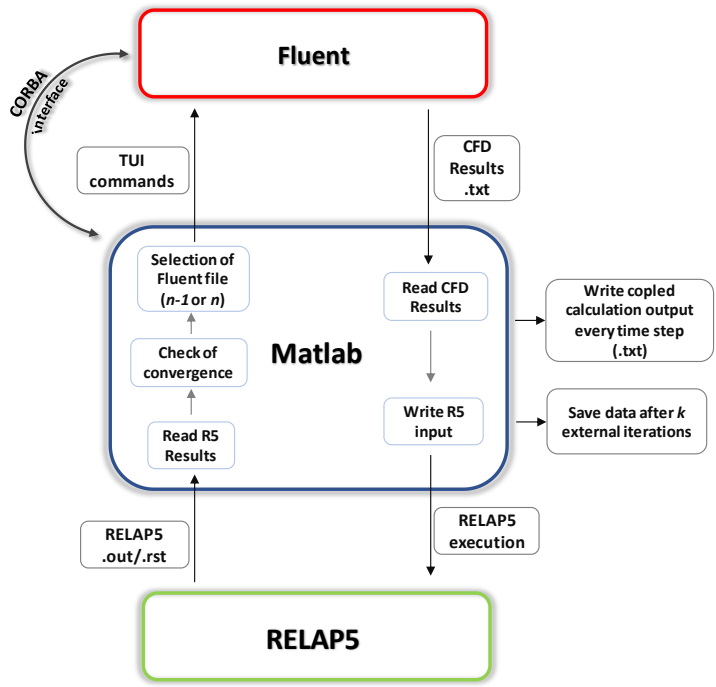

(b)

Figure 4: CIRCE-HERO computational domain for coupled calculations

\subsection{Coupling pre-test results obtained at UniPi}

Fluent/RELAP5 coupled simulations performed at UniPi were focused on the pre-test analysis of two different tests (Test-1 NC and Test-3 NC) whose initial and boundaries condition are reported in Table 2 and Table 3. In order to reduce the computational time for the coupled calculation, the initial steady state before the simulated transient is obtained imposing the initial $\mathrm{BC}$ for the mass flow rates ( $\dot{\mathrm{m}}$ and $\dot{\mathrm{m}}$ ) according to Table 2 in the CFD domain and obtained pressure $\mathrm{p}_{1}$ and $\mathrm{p}_{2}$ are then imposed in the RELAP5 nodalization prepared for the coupling. Starting from this steady state, the transient is simulated with the coupling tool, while for the RELAP5 stand-alone simulation, the initial steady state is also simulated. Hereafter, results obtained for CFD-STH coupled and STH stand-alone calculations are compared between them. In the comparison, experimental results for Test 1 are also reported to evaluate the general trend of the transient.

In Figure $5(a)$ the LBE mass flow rate inside the test section is reported for Test-1. Differences between experimental and numerical results in the steady state at full power are essentially due to different initial condition $(\sim 35 \mathrm{~kg} / \mathrm{s}$ for the experimental test vs $\sim 38 \mathrm{~kg} / \mathrm{s}$ imposed as boundary condition for the simulations). Then during the transition to natural circulation condition the LBE mass flow rate decreases to about $6.1 \mathrm{~kg} / \mathrm{s}$ in the experimental test calculated by the mass flow meter with a power supplied by the FPS of about $20.5 \mathrm{~kW}$. Results obtained by RELAP5 stand-alone and coupled calculations show a good agreement between them with differences less than $4 \%$ and reaching a value of about $3.7 \mathrm{~kg} / \mathrm{s}$ after about $1200 \mathrm{~s}$ after the transition, with a power supplied by the FPS of $22.5 \mathrm{~kW}$. The comparison between numerical results and experimental data shows differences of about $40 \%$. Numerical results show a different time trends compared to the experimental data. Indeed, the experimental mass flow rate reaches a steady state value after about $200 \mathrm{~s}$ from the simulated transient while the mass flow rate obtained from the coupled and RELAP5 stand-alone calculations tends to the experimental value after more than 3550s. To investigate this behaviour, the mass flow rate derived from a thermal balance (between inlet and outlet section of the FPS) is derived and reported in Figure $5(a)$. The value obtained shows a good agreement with the mass flow rate obtained numerically by the RELAP5 and coupled calculations with differences lower than $1 \%$ immediately after the transition while increasing the difference as time increases. Differences between the experimental mass flow rate and the one derived from the thermal balance should be investigated more exhaustively: the cause might be the thermal losses from the FPS toward the LBE in the pool.

Temperature at the inlet and outlet of the FPS are reported in Figure 5 (b). In the experimental Test 1, LBE temperature in the lower plenum of the facility is about $420^{\circ} \mathrm{C}$ while for RELAP5 and coupled calculations the average LBE temperature in the pool was assumed equal $400^{\circ} \mathrm{C}$ in agreement with the nominal conditions. Moreover, between the RELAP5 stand alone and coupled calculation a difference of about $4^{\circ} \mathrm{C}$ is evidenced at the beginning of the transient. The reason of this difference is the fact that in the STH stand-alone calculation all the duration of the test is simulated by the code and the temperature of about $404^{\circ} \mathrm{C}$ is foreseen by the code during the full-power steady state of the test (up to about $1800 \mathrm{~s}$ ). As the coupled simulation is concerned, the full power steady state is obtained imposing the nominal condition in agreement with the value reported in Table 2 (LBE initial temperature $400^{\circ} \mathrm{C}$ ). It is worth nothing that the temperature time trend predicted by RELAP5 stand-alone calculation remains constant at a value of $404^{\circ} \mathrm{C}$ for about $300 \mathrm{~s}$ after the simulated transient and then starts to decrease with a slope that is comparable with that shown in the experimental data. This behaviour is probably due to the fact the axial heat conduction is not accounted by the STH code and this results as an increased thermal inertial in the pool partially compensated by the lower temperature at the HERO outlet due to the higher water mass flow rate compared with the experimental value (see Figure 6 (a)). This might be also the cause of the higher slope of the temperature trend predicted by the coupled calculation.

Concerning the temperature trend of the LBE at the outlet section of the FPS, numerical pre-test calculations foresee a sharp decrease of the temperature $\left(\Delta \mathrm{T} \sim 67^{\circ} \mathrm{C}\right.$, Figure $\left.5(\mathrm{~b})\right)$. The reason of this behaviour might be a low thermal inertia of the structure of 
the FPS simulated in the numerical calculation. Figure 6 (b) shows the temperature contour plot (in ${ }^{\circ} \mathrm{C}$ ) in the lower plenum. The contour shows the cold plume reaching the bottom of the vessel and the temperature stratification in the lower plenum at $500 \mathrm{~s}$ after the transition.

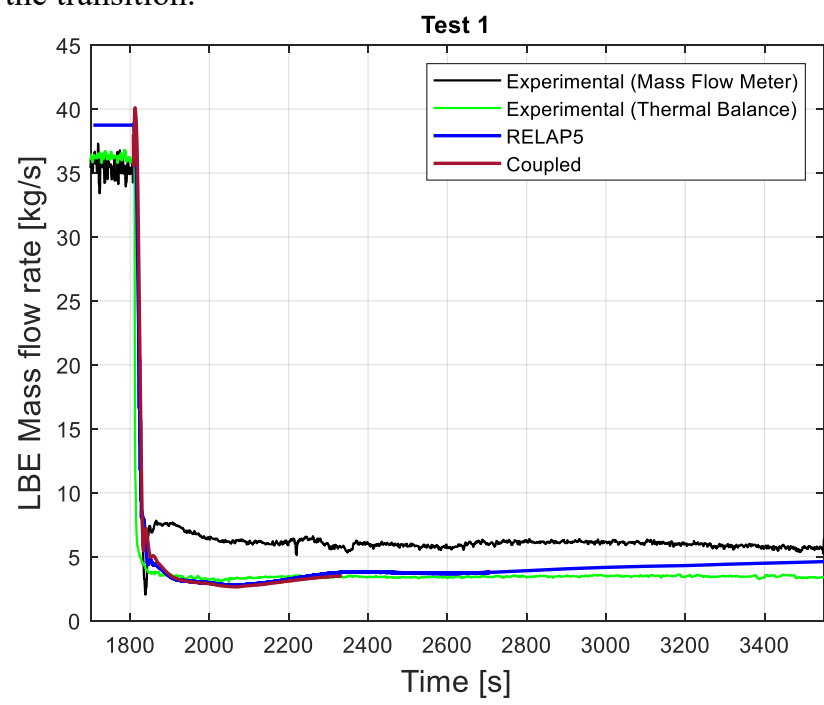

(a)

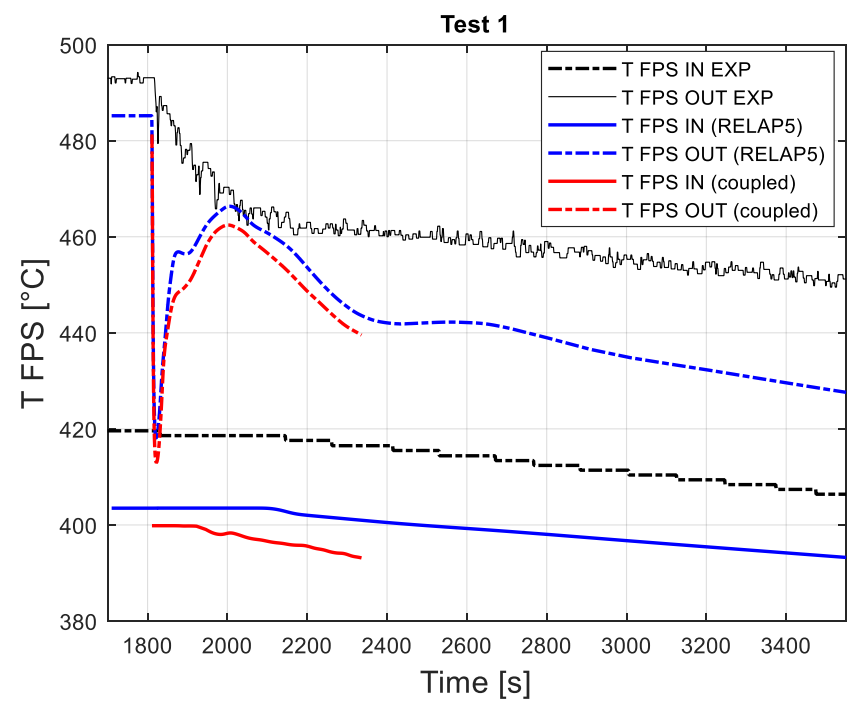

(b)

Figure 5: Comparison of LBE mass flow rate in the test section (a) and temperature profiles at the inlet/outlet of the FPS (b) Test 1

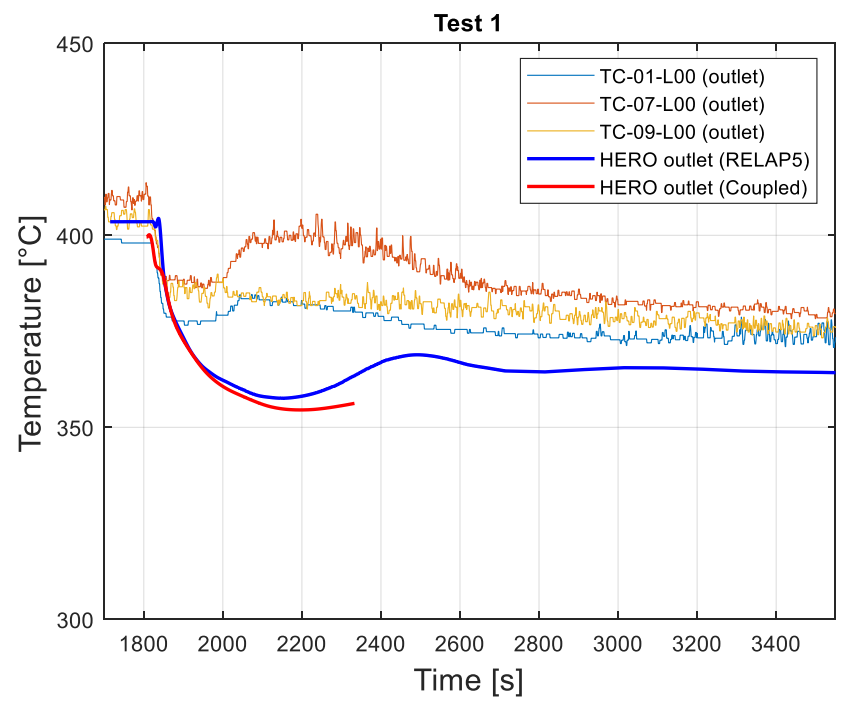

(a)

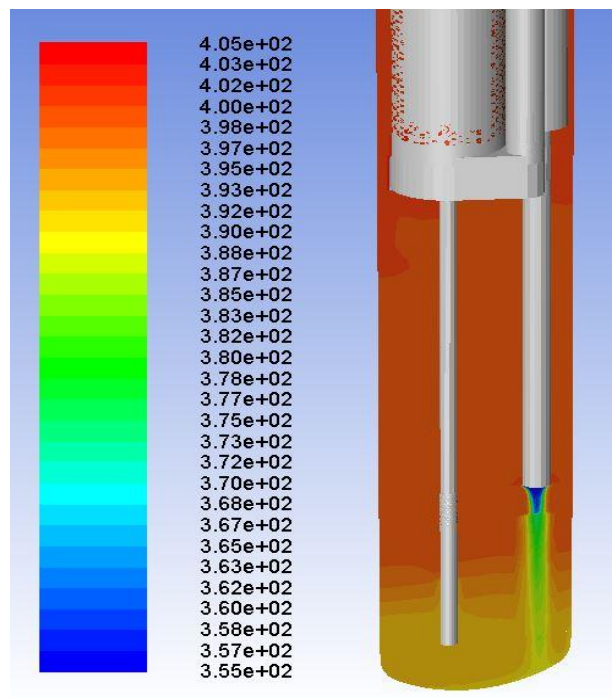

(b)

Figure 6: LBE temperature at the HERO outlet section (a) and LBE temperature $\left[{ }^{\circ} \mathrm{C}\right]$ contour in the lower plenum (b) Test 1

Concerning Test 3, the LBE mass flow rate is reported in Figure 7 (a). Coupled simulations are referred to the first $200 \mathrm{~s}$ after the transient. A good agreement is shown between the coupled and RELAP5 stand-alone calculation for the simulated transient. Comparing the RELAP5 stand-alone calculation and the experimental data the minimum in the LBE mass flow rate is obtained about $150 \mathrm{~s}$ after the minimum shown in the experimental results and the value obtained is about $6 \%$ higher than the minimum shown in the experiment $(\sim 3.03 \mathrm{~kg} / \mathrm{s})$. Then the mass flow rate increases for both experimental and numerical tests reaching at the steady state an average value of $5.98 \mathrm{~kg} / \mathrm{s}$ for the experiment and about $5.17 \mathrm{~kg} / \mathrm{s}$ for the RELAP5 simulation (these values are averaged in the range 3000-3500 s). Differences between the experimental mass flow rate measured by the mass flow meter and that computed by the thermal balance are evidenced also for Test 3 with differences of the order of $90 \%$. In Figure 7 (b) the temperature at the inlet of the FPS is reported. The LBE average temperature for the experimental Test 3 is higher compared to that imposed in the simulations according to the nominal conditions reported in Table 2 . As observed also in Test 1 , the FPS inlet temperature calculated by the RELAP5 stand-alone is almost constant for about $600 \mathrm{~s}$ before start to decrease (about $200 \mathrm{~s}$ more than what found in Test 1). These differences are due to the absence of the axial conduction in the RELAP5 code while differences with the Test 1 are essentially due to the different argon decreasing time trend. In fact, the reduction of the LBE mass flow rate is slower due to the slower reduction of the argon injection simulating the flywheel inertia of the pump causing a lower $\Delta \mathrm{T}$ across the HERO heat exchanger and hence maintaining the LBE temperature in the lower plenum for longer time.

Concerning the temperature trend at the outlet of the HX and reported in Figure 8 (a), RELAP5 stand-alone and coupled simulations predict an increasing of the temperature at the outlet section of the HX. This time trend shows differences compared with the previous Test 1 and with the experimental data in the first part of the simulated transient. This can be explained considering the effect of the reduction of the water injection in the secondary side of the HX and the fact that the argon decreases with a lower slope 
compared to Test 1 . During this transient the LBE temperature (calculated in the separator) remain practically constant for about 60 $\mathrm{s}$ after the simulated transient (see Figure 8 (b)). In this time interval the LBE enter in the heat exchanger with a constant temperature, the water flow rate is decreased, and the gas injection sustains the LBE flow rate longer compared to Test 1 (see Table 4). As a consequence, the temperature of the LBE increases showing a maximum $\left(\sim 445^{\circ} \mathrm{C}\right)$ at about $60 \mathrm{~s}$ after the transient, then the LBE temperature entering in the HX start to decrease as the consequence of the reduction of the power supplied to the FPS and the LBE temperature at the outlet of the HX decreases following the experimental time trend (Figure 8).

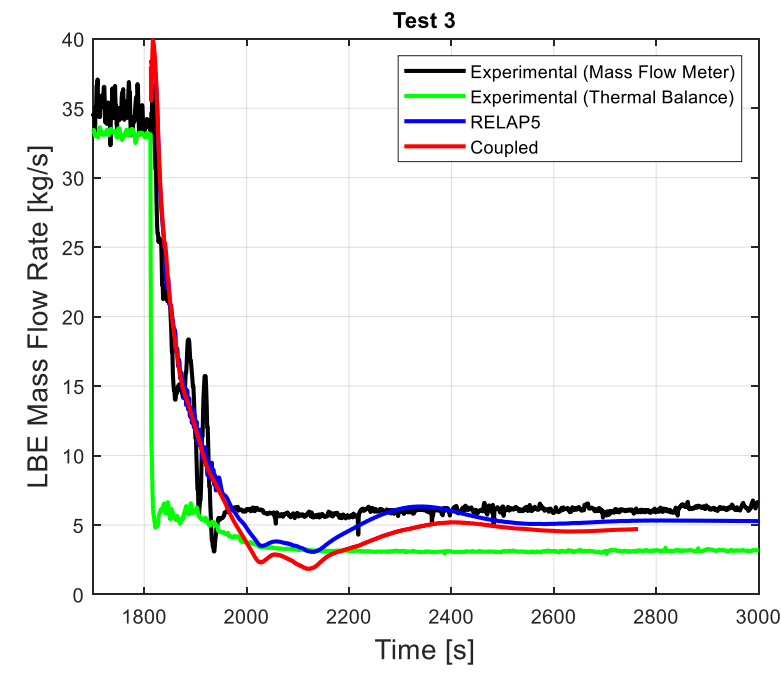

(a)

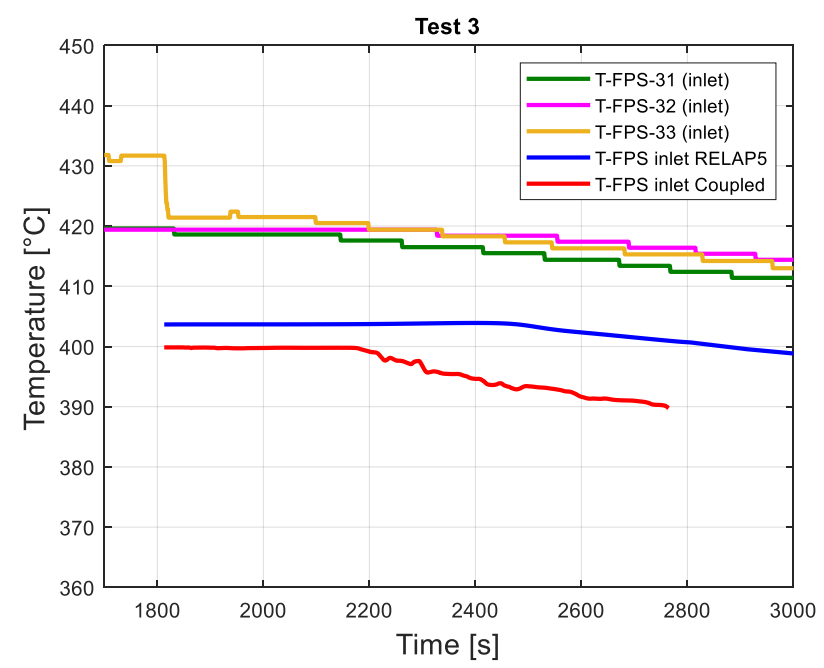

(b)

Figure 7: Comparison of LBE mass flow rate in the test section (a) and temperature profiles at the entrance of the FPS (b) Test 3

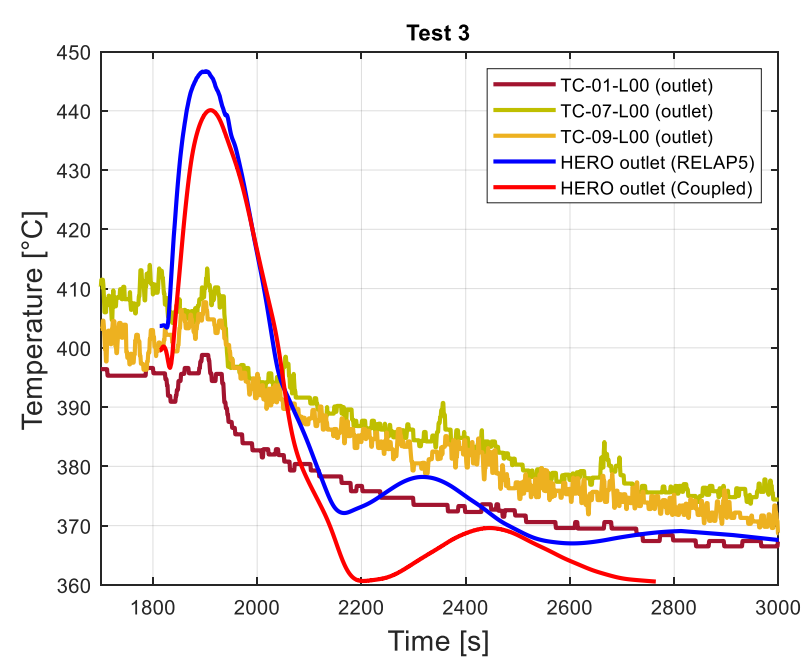

(a)

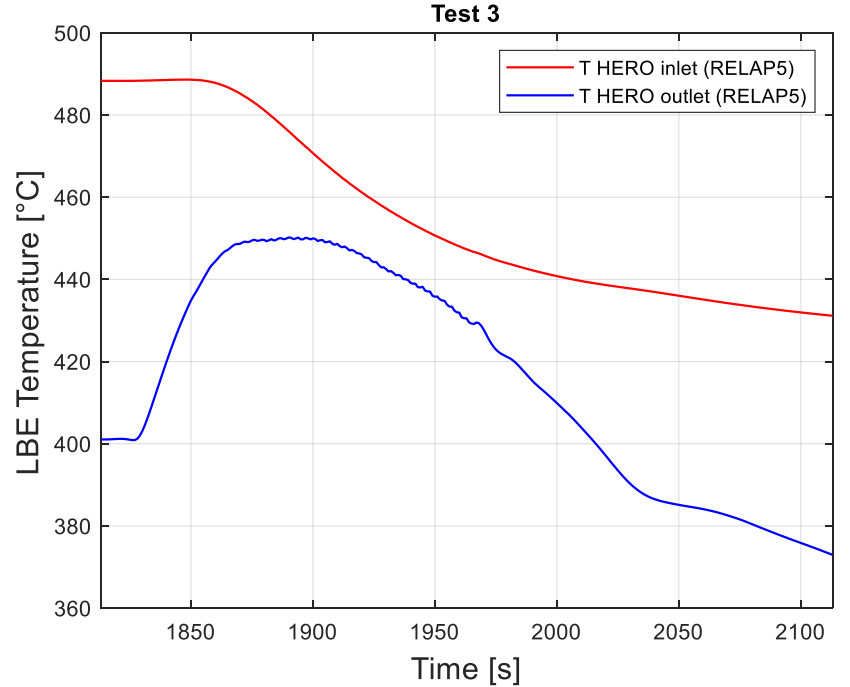

(b)

Figure 8: LBE temperature at the HERO outlet section Test 3

\section{POST-TEST SIMULATIONS AT NRG}

\subsection{SPECTRA stand-alone geometrical model}

The STH model of the CIRCE-HERO facility is modeled in the SPECTRA STH code (Stempniewicz, 2017) and comprises of the FPS (with feeding conduit), the fitting volume, the riser, the separator, the complete HERO SGTB heat exchanger together with secondary side and the LBE pool including all the heat structures representing the walls of the structures.

The nodalization of the STH model is shown in Figure 9. The main heat source in the CIRCE facility, the fuel pin simulator, is modeled with 10 axial heat structure nodes, with an additional node at each end representing mixing zones (CV-001 to 012). Furthermore, the feeding conduit and the release pipe of the facility are included in the model as four axial nodes before the FPS and three axial nodes after the FPS, respectively. The fitting volume is located above the release pipe and has been discretized into four nodes (CV-016 to 019), allowing both horizontal and vertical flow. The separator is modeled in a similar way, with the axial nodes in between these two structures representing the riser, i.e., CV-020 till CV-031.

The HERO-SGBT is the steam generator and corresponds to the heat sink of the system. It is modelled with 26 axial nodes and comprises of three segments, of which one is the LBE primary side (CV-201 to 226). The secondary side of the HERO-SGBT consists of 2 concentric rings in which water flows downwards (CV-598 to 625) and subsequently upwards (CV-626 to 653). The 
water flowing upwards is heated by the LBE through the outer HERO SGBT wall and eventually starts to boil. Feed water mass flow rate, temperature and pressure are prescribed at the inlet of the secondary side of HERO, i.e., at CV-598. Heat structures are also included to allow heat transfer between the three tubes. The same model is used for all seven tubes comprising the heat exchanger.

The LBE pool in which all the CIRCE-HERO subsystems are located has the same axial nodalization as the inner structures, except at the bottom, where only one control volume is used around the feeding conduit (CV-102). The control volumes comprising the pool are horizontally connected with the inner loop structures through heat structure walls to allow heat transfer between the inner loop and main pool. The thickness and properties of the heat structures are according to data given in Pesetti et al. (2018a). Sections of which the wall consists of more than one material, e.g., the riser, which has a layer of air between two concentric metallic cylinders, contain more heat structures than those consisting of a single material, like the fitting volume whose wall is made of AISI 304 only.

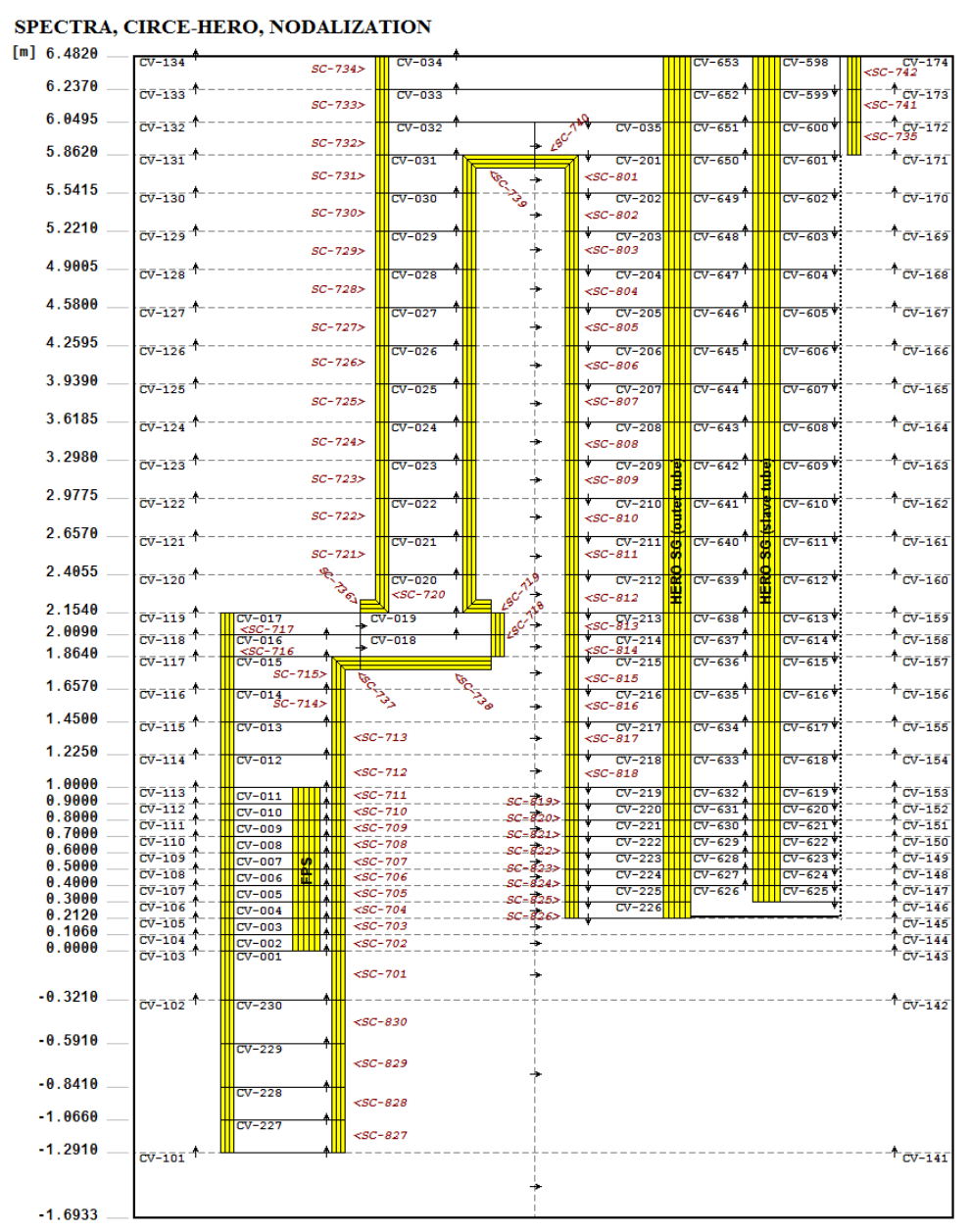

Figure 9: CIRCE-HERO SPECTRA nodalization

\subsection{CFD geometrical model}

The CFD code ANSYS CFX is used to model the main pool and vessel of the CIRCE-HERO facility. The CAD used in the CFD simulations is shown in the right of Figure 10. The internal elements indicated by the arrows are removed from the CAD, so that only the region between the external vessel wall and the structure walls remains, i.e., the main pool. The CFD geometry only extends up till the free surface to avoid multi-phase flow calculations. The non-wall resolved mesh used for the CFD calculations, which is depicted in the right of Figure 10 for the area around the separator, consists of in total 1.8M cells. Most of these cells are hexahedral shaped, though difficult regions with corners, such as in the bottom of the vessel, contain tetrahedral cells.

The velocity field is solved using the RANS SST k- $\omega$ turbulence model with automatic wall functions, while the thermal energy model is used to produce the temperature field. As the liquid in question is a heavy metal, a turbulent Prandtl number of 2.0 is used (Bricteux et al., 2012). 

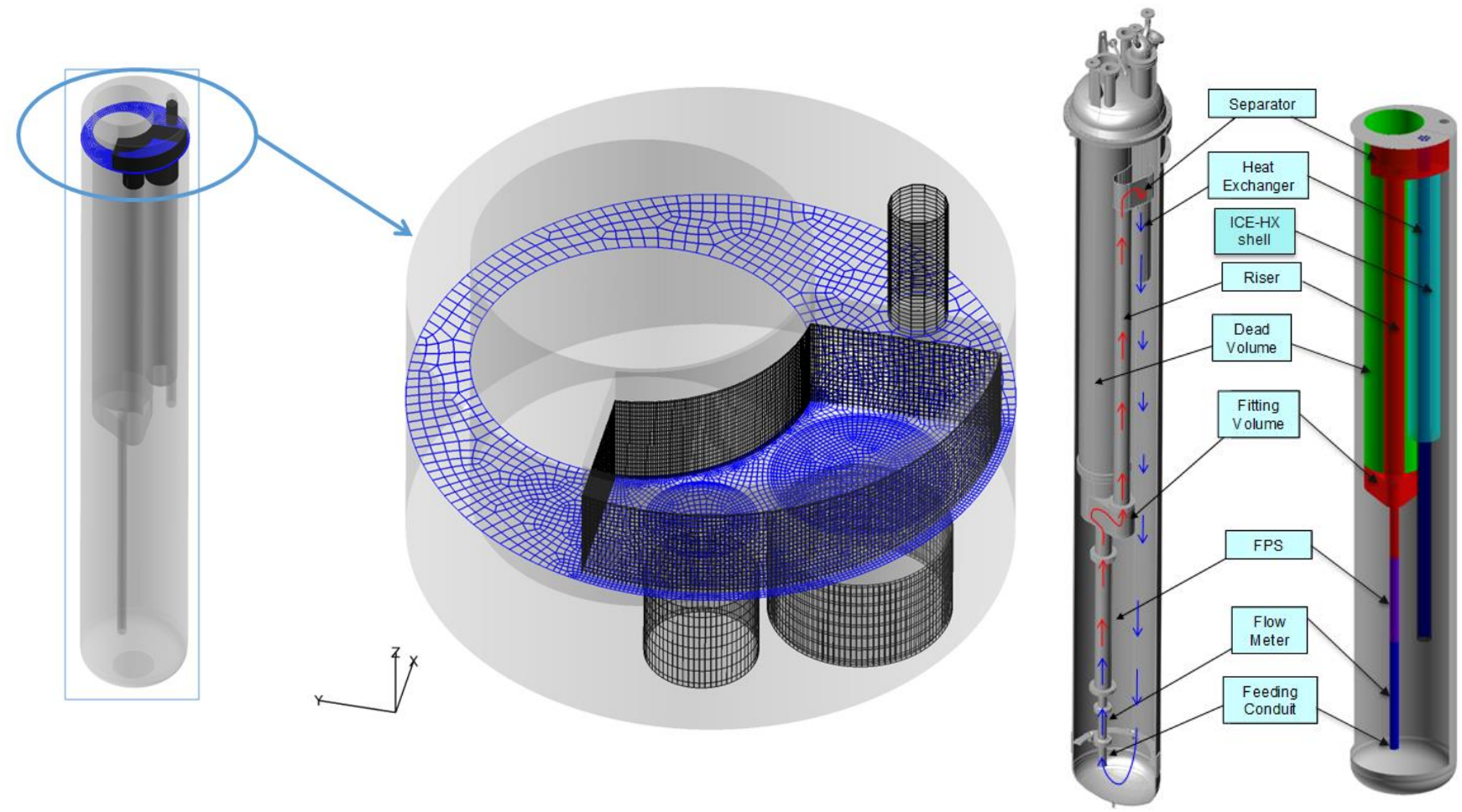

Figure 10: CIRCE-HERO CFD computational model

\subsection{CFX-SPECTRA coupling procedure}

The coupling approach used for the CFX-SPECTRA coupled calculations is based on a domain-overlapping two-way approach and is schematically depicted in Figure 11. Temperature of the LBE is exchanged between the two codes on the inlet and outlet of the CFD domain, i.e., SPECTRA provides CFX with a temperature at the outlet of HERO (inlet of CFX), while CFX in return couples the temperature of LBE at the FPS inlet (CFX outlet) back to SPECTRA. SPECTRA also provides the LBE mass flow rate at HERO's outlet to CFX. As the inner loop has only one inlet and outlet, this mass flow rate is also used at the FPS inlet as boundary condition for the CFD code.

To get a proper stratification inside the main pool, various independent tests were performed regarding the exchange of thermal data from SPECTRA's inner loop to CFX' pool. It was found that the best results are obtained when SPECTRA feeds a thermal heat flux over the inner loop's wall to CFX, with CFX providing a wall temperature back to SPECTRA. In this way, the inner loop's walls do not need to be present inside the CFD simulation. For efficiency purposes, CFD's geometry is axially subdivided in volumes matching those used for SPECTRA's nodalization, as can be seen in Figure 11. It should be noted that even though SPECTRA's model includes the pool, the pool's temperatures are overwritten by those coming from CFX and hence not used in the coupled simulation.

Data is exchanged at the end of each time-step of CFX via external data exchange routines. Based on a convergence study, this time-step is fixed at $0.05 \mathrm{~s}$. The RMS courant number in CFX is around 0.3 at the start of the transient simulation and decreases as the simulation progresses due to the decreasing LBE mass flow rate. SPECTRA uses a variable time-step, programmed such that it stops at each multiple of $0.05 \mathrm{~s}$, checking for a new data-exchange file. Both codes verify the time-step when reading the data file.

\subsection{Coupling post-test results obtained at NRG}

CFX-SPECTRA coupled simulations performed at NRG were focused on the post-test analysis of test 3, whose initial and boundaries conditions are reported in Table 5Table 2 and Table 3 and 4, respectively. As mentioned in Section 2, the initial conditions used during the experiment are different than those initially planned. The reason for this is that while performing the experiment, it was noticed that the LBE in the pool was heating up too much. Therefore, it was decided to decrease the power of the FPS. However, by the time the temperature was regulated, the pool had already warmed up more than initially planned.

Besides affecting the initial conditions, this also affected the evolution of the test. Initially, it was foreseen that test 3 would last one hour, with the first 30 minutes the system operating at steady-state conditions and the second half simulating a PLOFA scenario. However, adjusting the FPS power prevented the system from ever reaching a stable steady-state. This is clearly visible in Figure 12, which shows the mass flow rate through the inner loop and the inlet temperature of the steam generator as function of time for the full duration of the test. These two parameters should be constant during the first $1800 \mathrm{~s}$ of the test, but, as can be seen, they are slowly changing during the first half of the experiment. Furthermore, it resulted in the power removed by HERO to actually exceed the power supplied by the FPS during the test, meaning the whole system is slowly decreasing in temperature. Normally, a thermal balance would occur, but unfortunately, the system did not have enough time to reach this state. 


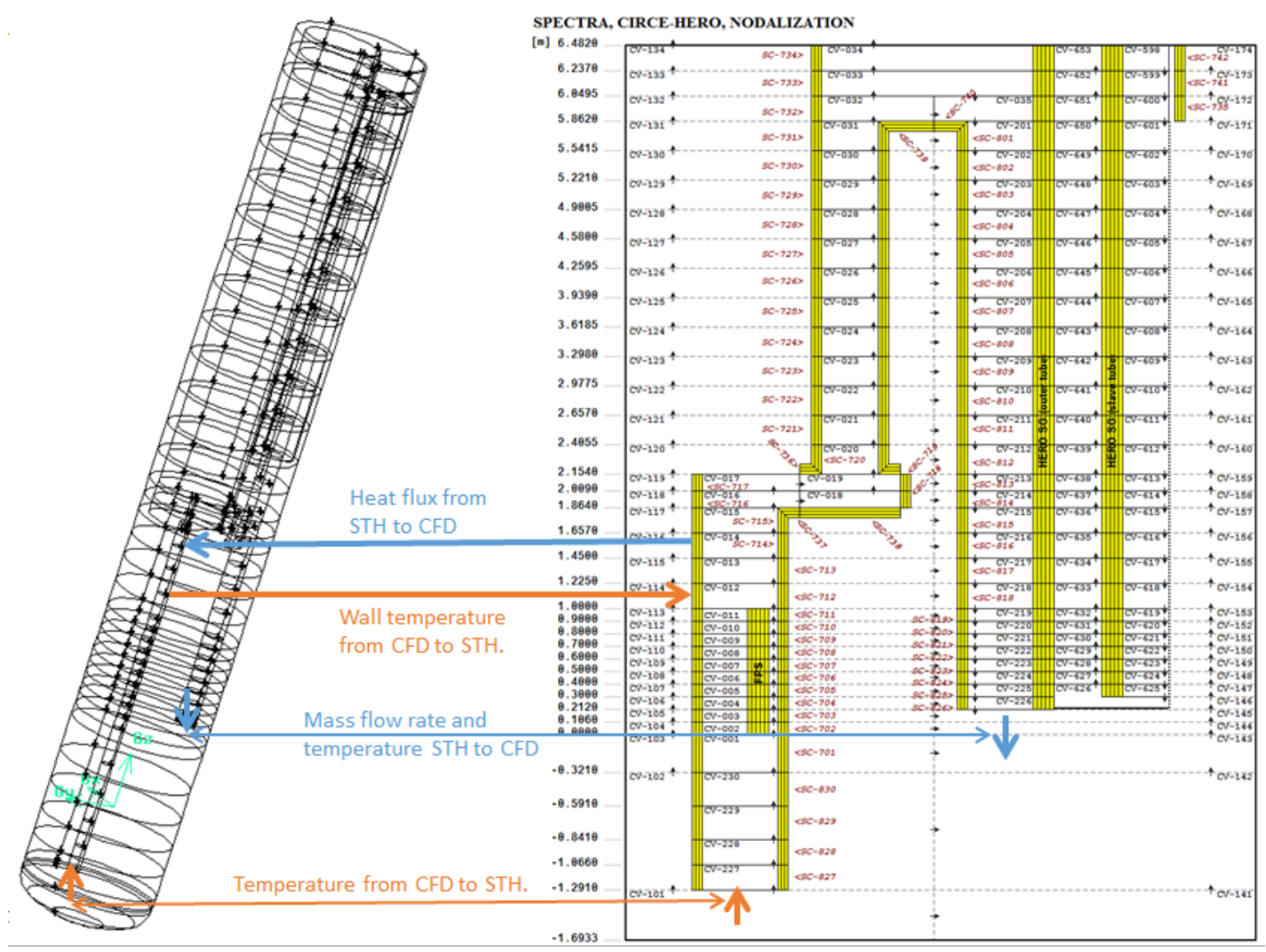

Figure 11: CIRCE-HERO computational domain for CFX-SPECTRA coupled calculations

Experimental data test 3

mass flow rate and HX inlet temperature

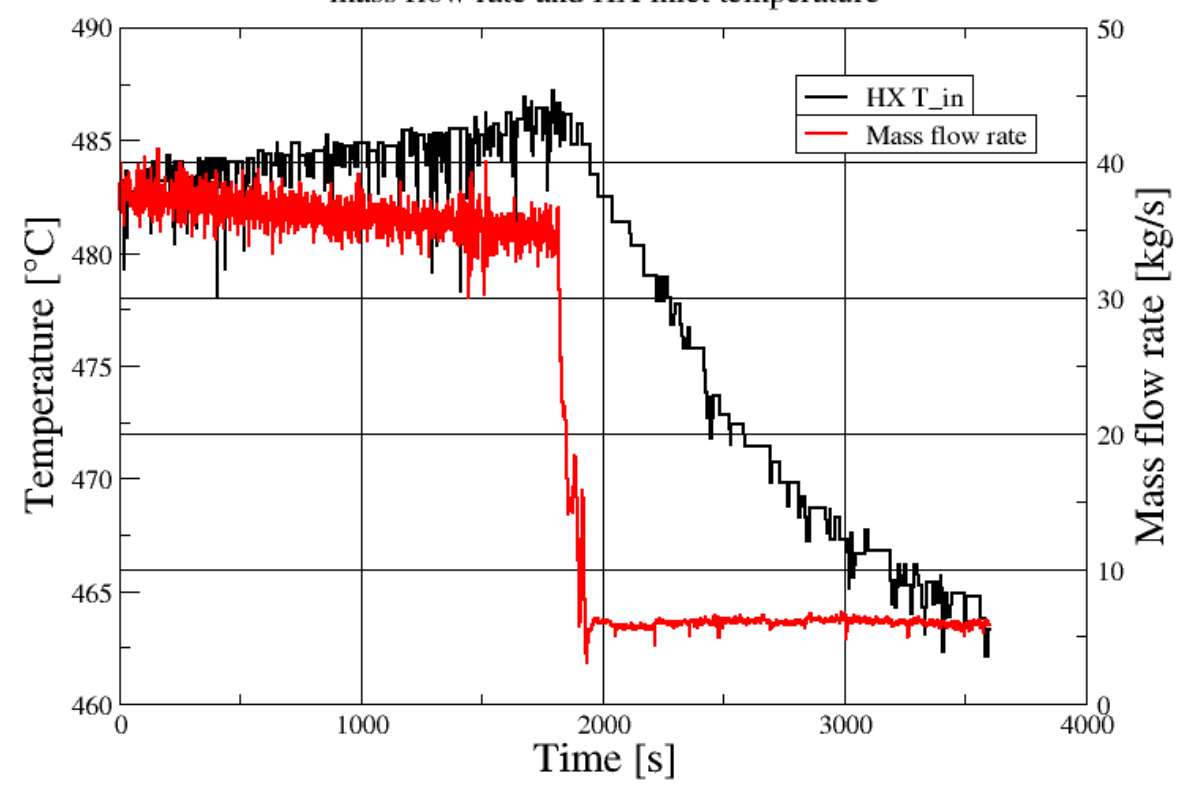

Figure 12: Experimental data obtained during test 3.

The experiment not reaching a steady-state affects the simulation in two ways: 1) there is no proper initial state to start a transient simulation from, and 2) the history of an experiment influences its evolution; with the history missing it becomes extremely challenging to correctly capture the intended transient. To nonetheless perform a simulation of the test 3 PLOFA experiment, and asses the performance of the coupled simulation, it was decided to recreate as closely as possible the system's state at the start of the transient, i.e., at $\mathrm{t}=1800 \mathrm{~s}$. Hereto, first a stand-alone STH run was performed. It was stopped when the inner loop's temperature and mass flow rate matched those of the experiment closely enough. Then it was coupled to CFX, whose pool temperature was initialized according to the experimental stratification. A coupled run was subsequently performed, with the STH side frozen to prevent the pool from cooling. When the system had convergence, it was stopped. The resulting flow and temperature fields are then used as initial 
fields of the simulation of the second part of test 3 . Only $900 \mathrm{~s}$ of that part were simulated, i.e., from $\mathrm{t}=1800 \mathrm{~s}$ till $\mathrm{t}=2700 \mathrm{~s}$, due to time restrictions.

In the left of Figure 13 the experimental and numerical mass flow rate through the inner loop as function of time is plot. As can be seen, the initial value is quite a bit lower in the simulation $(\sim 28 \mathrm{~kg} / \mathrm{s})$ when compared with the experiment $(\sim 34 \mathrm{~kg} / \mathrm{s})$. This is a result of the coupling not having started from an actual coupled steady-state but more a forced steady-state, as previously discussed. The trend afterwards is well predicted, with the final value of the simulation matching that of the experiment well. It should be noted that the mass flow rate is prescribed in the simulation, according to Table 4 . This obviously enhances the "predictive" capacity of the model. However, even though the mass flow rate is prescribed, it does not instantaneously match the prescribed value due to the inertia of the flow. This is particularly visible in the first $200 \mathrm{~s}$ of the transient, where the mass flow rate from the simulation decreases slower than in the experiment.

The temperature at the outlet of the HERO test section is shown in the right of Figure 13. Three lines of the experiment are shown, corresponding to the three thermocouples installed at that location. The general evolution of the temperature is recovered by the model, with an initial increase in temperature followed by decrease before the temperature slowly moves towards an equilibrium value corresponding to the thermal balance of the system. The values are quite different in the simulation than in the experiment though, with the temperature rise and subsequent drop much more pronounced in the model than in the test and the final temperature being about $25-30^{\circ} \mathrm{C}$ lower. One of the possible causes for the discrepancy is how the temperature is coupled. SPECTRA provides CFX with a temperature at HERO's outlet. SPECTRA being a 1D code, there is no special distribution to this temperature. So at CFX's inlet, which is the outlet of HERO, the LBE has a uniform temperature, while in reality, the temperatures at the wall are higher than at the centre due to the lower mass flow rate at the walls.

Another plausible cause of the difference between the experiment and simulation is the lack of a clear steady-state at the start of the transient of the experiment, as previously discussed. Furthermore, the experimental feed water inlet temperature shows a dip at the start of the transient, before returning to its initial value. A decreased feed water inlet temperature results in a lower temperature on the LBE side. In the simulation, this value is kept constant throughout the whole run. Finally, the sudden decrease in LBE mass flow rate could result in back flow of cold LBE into HERO (Moreau et al., 2018). This obviously results in a lower temperature at that location. In the simulations, back flow is not possible. It is interesting to see though that this strong overshoot in LBE temperature at HERO's outlet is found both by the Fluent-RELAP5 coupled model as well as by the CFX-SPECTRA coupled model, suggesting that either both models fail to catch the phenomena preventing this, or that some boundary conditions, like the feed water inlet temperature, are incorrectly incorporated.

Looking at the temperature evolution at HERO's outlet during the last 300-400 s though, the simulation has a similar decrease as the experiment. In this part of the test, the mass flow rates of the LBE and steam generator secondary side have settled to constant values, meaning that temperature changes are mainly caused by a thermal imbalance of the system. A decreasing temperature indicates a heat loss to the environment. As the slope of the simulation matches that of the experiment reasonably well, it indicates these environmental heat losses are decently well captured.

The FPS inlet temperature is shown in the left of Figure 14. The value in the simulation is slightly below that of the experiment at the start, and a stronger decrease is found during the time span of the test. This is a result of the colder temperature coming out of HERO, which slowly spreads to the bottom of the pool and to the inlet of the FPS.

Finally, pool stratification plots are shown for various instances of time in the right of Figure 14 and in . In general, a good match is found with the experimental data; the temperatures in the top, the location of the strong stratification and the temperature difference between the upper part of the pool and bottom part are recovered well. Only at the end of the simulation, at $t=900 \mathrm{~s}$, is the temperature in the bottom of the pool quite a bit lower in the model than in the experiment. This once more is a result of HERO's lower outlet temperature.

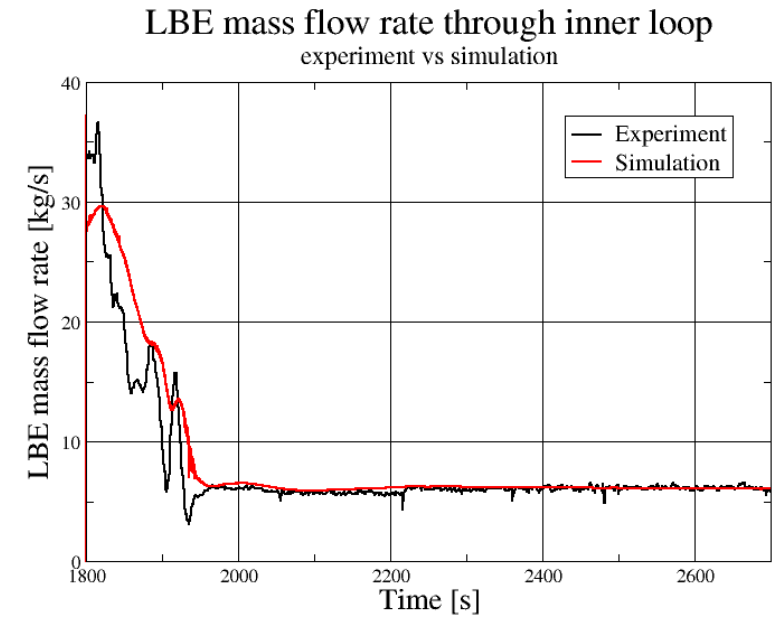

(a)

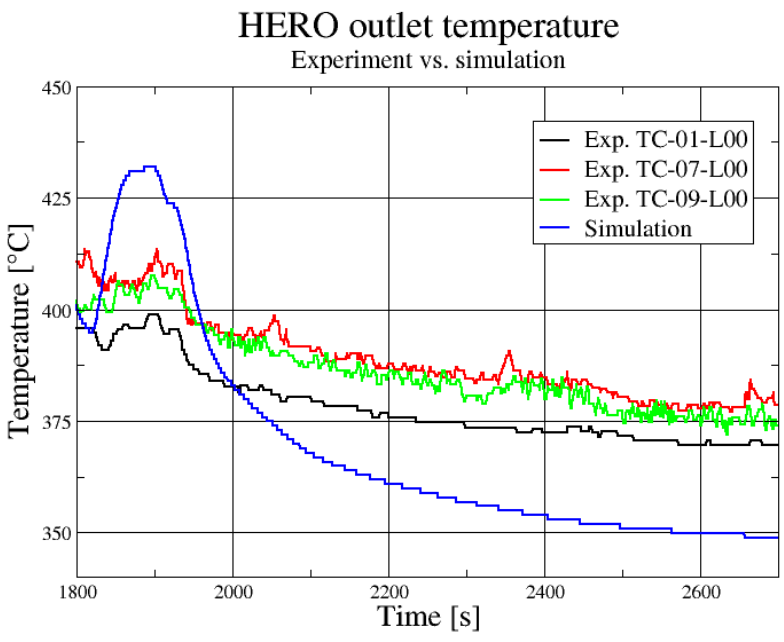

(b)

Figure 13: Comparison of LBE mass flow rate in the test section (a) and temperature profiles at the outlet of HERO (b) Test 3 


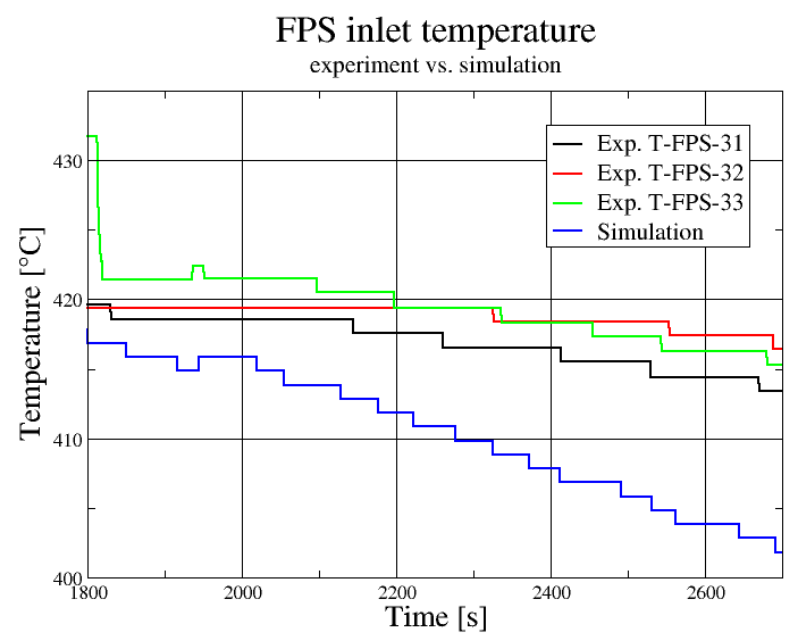

(a)

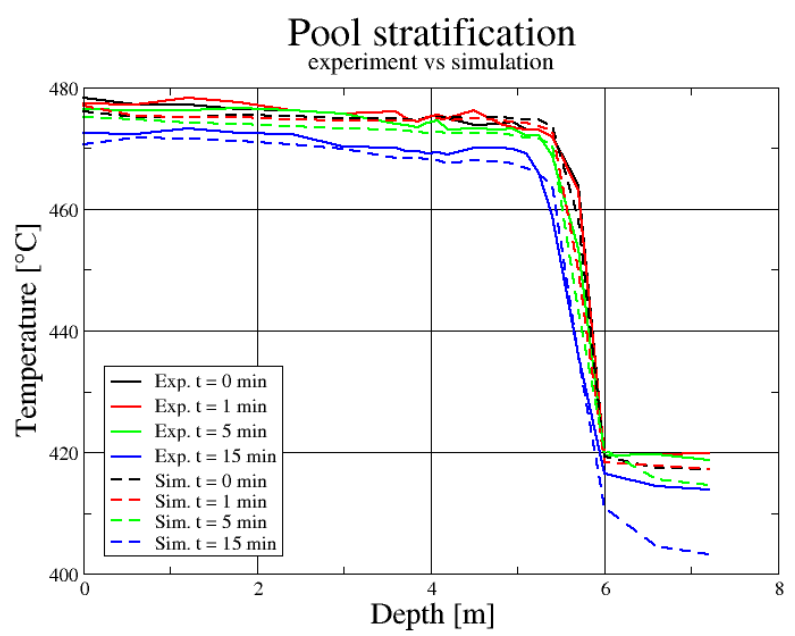

(b)

Figure 14: LBE temperature at the entrance of the FPS (a) and LBE temperature contours in the pool at various times (b) Test3
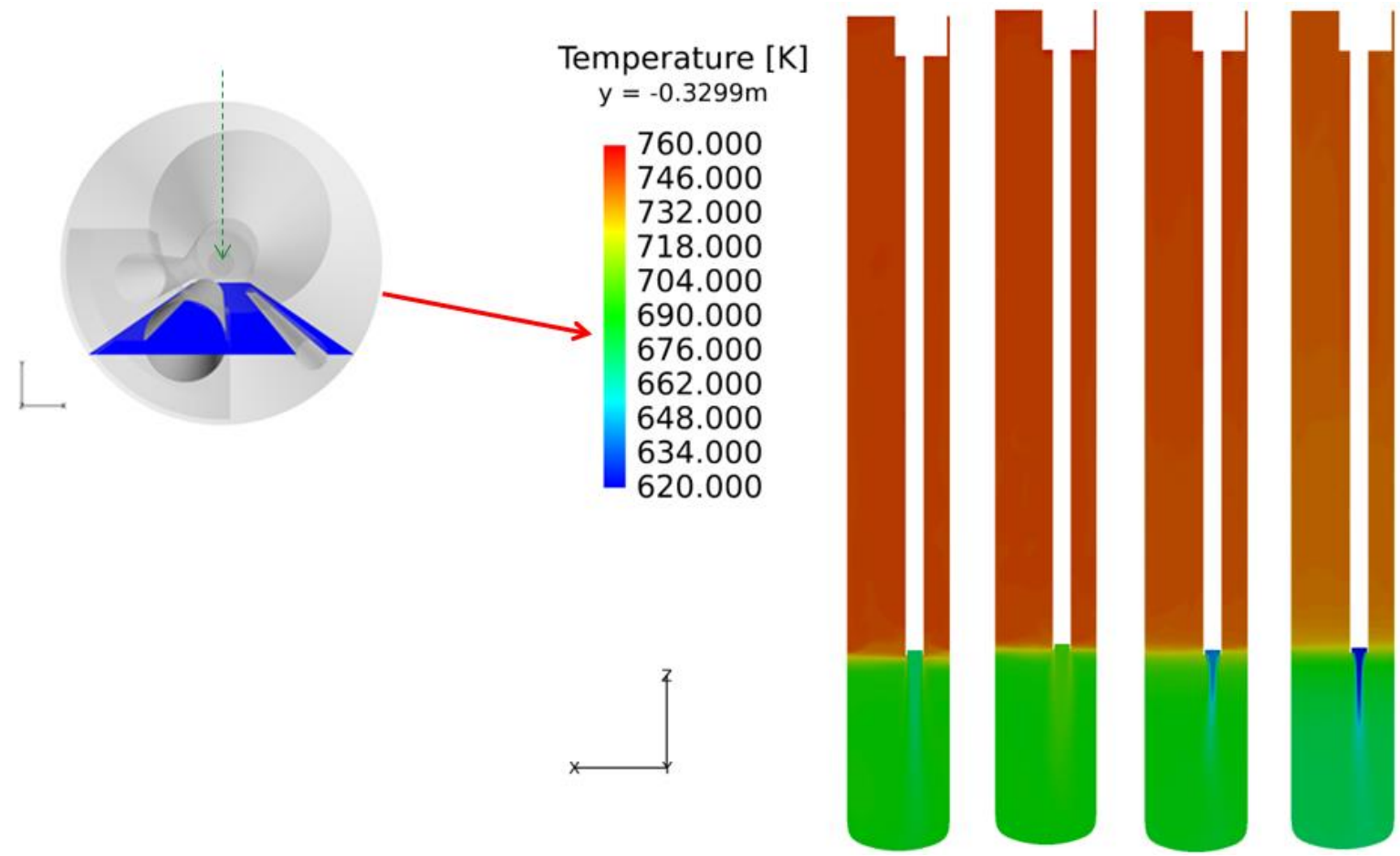

Figure 15: LBE temperature contours in the pool at various times on a vertical plane through HERO for test 3.

\section{CONCLUSIONS AND RECOMMENDATIONS}

The present paper describes two coupled CFD-STH models created of the CIRCE-HERO facility, one created by UniPi which couples ANSYS Fluent with RELAP5 and another one developed by NRG which couples ANSYS CFX with the in-house developed STH code SPECTRA. As part of the H2020 project SESAME a series of experiments were performed with the CIRCE-HERO facility, both for nominal steady-state settings as for accident scenarios. The purpose of these experiments was twofold: 1) provide data for liquid metal fast reactor designs and 2) generate a database to validate coupled CFD-STH models with. The current papers focuses on the second part.

For the validation phase, UniPi selected two protected loss of flow accident scenario experiments. Stand-alone STH simulations were also performed of these two experiments for further comparison. The coupled and STH models give similar results, though the coupled model has slightly lower temperature because of the imposed BC in agreement with the nominal conditions foreseen in the experimental campaign. Exact comparison of the models with experimental data is difficult, as the experimental settings are different than those initially foreseen. However, the general flow and temperature evolution that is found in the experiment is well recovered by the models. Furthermore, taking the discrepancy between the experimental and numerical initial temperature into account, the values for the temperatures match well.

NRG modelled one protected loss of flow accident scenario, though it did use post-test initial conditions. The modelled main pool stratification evolution matches well with the experimental one. Only towards the end of the simulated test, differences are found in 
the bottom region of the pool, below the outlet section of HERO HX. This is a result of the lower outlet temperature of HERO when compared with the experiment. This difference also affects the inlet temperature of the FPS, which is below that of the experiment. Possible explanations of the lower temperature are: 1) 1D boundary condition used as inlet for the 3D CFD model, 2) lower experimental feed water inlet temperature and 3) non-existence of a real steady-state before the start of the transient part of the experiment.

An interesting observation is that both coupled models show similar overshoots in the HERO outlet temperature, something which is not, as much, seen in the experiment. This could either indicate that a particular 3D phenomenon is not recovered by the STH part of the coupled model or some missing data from the experiment, e.g., the feed water inlet temperature. More investigation is needed to be sure of the exact cause. This also highlights the importance of proper experiments and experimental data to validate numerical simulations with.

The obtained results show that the coupling of a CFD code with an STH code is a promising methodology that deserves further investigation and qualification to be used as a tool in the design of nuclear power plants.

\section{ACKNOWLEDGMENT}

The authors would like to thank the European Commission for its financial support within the HORIZON2020 MYRTE ( ${ }^{\circ}$ 662186) and SESAME programs ( $\left.{ }^{\circ} 654935\right)$.

\section{REFERENCES}

Angelucci M., Martelli D., Barone G., Di Piazza I., Forgione N., 2017. STH-CFD codes coupled calculations applied to HLM Loop and Pool system, Science and Technology of Nuclear Installations (2017), Article ID 1936894.

Bandini, G., Di Piazza, I., Gaggini, P., Del Nevo, A, Tarantino, M., 2011. CIRCE experimental set-up design and test matrix definition, ENEA UTIS-TIC Technical Report, IT-FS-001, 28.02.2011.

Bricteux, L., Duponcheel, M., Winckelmans, G., Tiselj, I., and Bartosiewicz, Y. 2012. Direct and large eddy simulation of turbulent heat transfer at very low Prandtl number: Application to lead-bismuth flows. Nuclear Engineering and Design, vol. 246, pp.. 91-97.

Frignani, M., et al., 2017. ALFRED: A Strategic Vision for LFR Deployment, Proceedings of ANS Winter-Meeting.

Martelli D., Forgione N., Barone G., Di Piazza I., 2017. Coupled simulation of the NACIE facility using RELAP5 and ANSYS FLUENT codes Annals of Nuclear Energy 101 (2017)201 408-418.

Moreau, V., Zwijsen, K, and Lampis, S. 2018. CIRCE Experiment: CFD model validation. SESAME deliverable 3.4.

Pesetti A., 2018. CIRCE-HERO Test Facility: Heat Losses Characterization Tests. Ref. CI-I-R-351.

Pesetti, A., Forgione N., Narcisi, V., Lorusso, P., Giannetti, F., Tarantino, M., and Del Nevo, A., 2018a. ENEA CIRCE-HERO Test Facility: Geometry and Instrumentation Description. Report ENEA CI-I-R-343.

Rozzia D., Pesetti A., Del Nevo A, Tarantino M., Forgione N., 2017. HERO test section for experimental investigation of steam generator bayonet tube of ALFRED, International conference on Nuclear Engineering, Proceedings ICONE 25 Shanghai China.

SESAME Project, EURATOM H2020, Grant Agreement N. 654935, April 2015.

Stempniewicz, M.M., "SPECTRA Sophisticated Plant Evaluation Code for Thermal-Hydraulic Response Assessment, Version 3.61, November 2017”, NRG report K6202/MSt-1771112, Arnhem, November 24, 2017. SPECTRA code.

Tarantino, M., Agostini, P., Benamati, G., Coccoluto, G., Gaggini, P., Labanti, V., Venturi, G., Class, A., Liftin, K., Forgione, N., Moreau, V., 2011. Integral circulation experiment: thermal-hydraulic simulator of heavy liquid metal reactor. J. Nucl. Mater. 415, 433-448.

Tarantino M., Martelli D., Barone G., Di Piazza I., Forgione N., 2015. Mixed Convection and stratification phenomena in a heavy liquid metal pool, Nuclear Engineering and Design 286 (2015), 261-277. 